\title{
O MOVIMENTO NEGRO BRASILEIRO INDAGA E DESAFIA AS POLÍTICAS EDUCACIONAIS
}

\author{
Nilma Lino Gomes ${ }^{1}$
}

Resumo: O artigo discute os limites e os avanços do Movimento Negro brasileiro em prol de uma educação antirracista. Analisa as mudanças e o aprimoramento da capacidade de articulação desse movimento social com base no processo de redemocratização do Brasil, principalmente nos momentos de aprovação da Constituição Federal de 1988 e da Lei de Diretrizes e Bases da Educação (LDB). Aponta a reconfiguração do Movimento Negro diante das disputas políticas travadas no Brasil democrático para que a questão racial fosse reconhecida como legítima e incorporada àpolítica educacional. Ressalta duas características importantes do Movimento Negro que indagam e desafiam as políticas educacionais, a saber: o seu caráter educativo e a resistência democrática.

Palavras-chave: Educação; Movimento Negro; Política Educacional; Antirracismo; Democracia.

\section{THE BRAZILIAN BLACK MOVEMENT INQUIRIES AND CHALLENGES EDUCATIONAL POLICIES}

\begin{abstract}
The article discusses the limits and advances of the Brazilian Black Movement in favor of an antiracist education. It analyzes the changes and the improvement of the capacity of articulation of this social movement based on the process of redemocratization of Brazil, mainly in the moments of approval of the Federal Constitution of 1988 and of the Law of Guidelines and Bases of Education (LDB). It points to the reconfiguration of the Black Movement in the face of political disputes in democratic Brazil, so that the educational politics recognized as legitimate and incorporated the racial question. It highlights two important characteristics of the Black Movement that investigate and challenge educational policies, namely their educational character and democratic resistance.
\end{abstract}

Key-words: Education; Black Movement; Educational Politics; Anti-racism; Democracy.

\section{LE MOUVEMENT NOIR BRÉSILIEN ENQUIERT ET DÉFIS LES POLITIQUES ÉDUCATIVES}

Résumé: L'article traite des limites et des avancées du Mouvement Noir brésilien en faveur de une éducation antiraciste. Il analyse les changements et l'amélioration de la capacité d'articulation de ce mouvement social en basé sur le processus de redémocratisation au Brésil, principalement au moment de l'approbation de la Constitution Fédérale de 1988 et de la Loi sur les Directives et les Bases de l'Éducation (LDB). Il évoque la reconfiguration du Mouvement Noir face aux conflits politiques travées dans un Brésil démocratique pour que la question raciale soit reconnue comme légitime et intégrée dans la politique de l'éducation. Il met en évidence deux caractéristiques importantes du Mouvement Noir qui enquièrent et défient les politiques éducatives, à savoir: leur caractère éducatif et la résistance démocratique.

\footnotetext{
${ }^{1}$ Pós-doutorado em Sociologia pela Universidade de Coimbra (Portugal) e pela Universidade Federal de São Carlos (UFSCar). Professora Titular da Faculdade de Educação da Universidade Federal de Minas Gerais (UFMG). Integrante do Programa Ações Afirmativas na UFMG. Bolsista de Produtividade Científica do CNPq. E-mail:
}

Revista da ABPN • v. 11, Ed. Especial - Caderno Temático: Raça Negra e Educação 30 anos depois: e agora, do que mais precisamos falar? • abril de 2019, p.141-162

DOI 10.31418/2177-2770.2019.v11.c.1.p141-162 
Mots-clés: Éducation; Mouvement Noir; Politique Éducative; Antiracisme; Démocratie.

\section{EL MOVIMENTO NEGRO BRASILEÑO INDAGA Y DESAFIA LAS POLÍTICAS EDUCACIONALES}

Resumen: El artículo discute los límites y los avances del Movimiento Negro brasileño en favor de una educación antirracista. Se analiza los cambios y el perfeccionamiento de la capacidad de articulación de ese movimiento social con base en el proceso de redemocratización de Brasil, principalmente en los momentos de aprobación de la Constitución Federal de 1988 y de la Lei de Diretrizes e Bases da Educação (LDB, Ley de Directrices y Bases de la Educación). Apunta la reconfiguración del Movimiento Negro ante las disputas políticas trabadas en el Brasil democrático para que la cuestión racial fuera reconocida como legítima e incorporada a la política educativa. Resalta dos características importantes del Movimiento Negro que indagan y desafían las políticas educativas, a saber: su carácter educativo y la resistencia democrática.

Palabras-clave: Educación; Movimiento Negro; Política Educativa; Anti-racismo; Democracia.

\section{UM PROTAGONISMO QUE VEM DAS LUTAS COTIDIANAS}

As lutas sociais nos reeducam. É por meio delas que a resistência à opressão é construída e se retroalimenta. E é nesse tipo de resistência, no Brasil, que foram e são forjados os ensinamentos e os aprendizados advindos dos movimentos sociais.

Mesmo em tempos de democracia em crise, não podemos deixar de contabilizar as muitas conquistas dos movimentos sociais em prol de uma sociedade mais justa. Destaco, dentre essas, os avanços alcançados pela luta antirracista e pelos direitos da população negra, no Brasil, tais como: a obrigatoriedade do ensino de História e Cultura Afro-Brasileira e Africana (Lei n.9.394/96, alterada pela Lei n.10.639/03),a regularização das terras quilombolas (Decreto n.4.887/03), o Estatuto da Igualdade Racial (Lei n.12.288/10), o princípio constitucional das ações afirmativas aprovado por unanimidade pelo plenário do Supremo Tribunal Federal (STF), em 2012, a Lei de Cotas Sociorraciais nas instituições públicas federais de ensino médio e superior (Lei n.12.711/12), a Lei de Cotas Raciais nos Concursos Públicos (Lei n.12.990/14), a ampliação das denúncias de violência religiosa, o reconhecimento social do genocídio da juventude negra e do feminicídio negro, as iniciativas governamentais em prol da saúde da população negra(Política Nacional de Saúde Integral da População Negra, instituída pela Portaria n. 992, de 13/5/95), dentre outras.

Nada disso aconteceu por mérito do Estado brasileiro. Pelo contrário, ele foi e continua sendo duramente pressionado e tensionado pelo Movimento Negro,

Revista da ABPN • v. 11, Ed. Especial - Caderno Temático: Raça Negra e Educação 30 
Quilombola, de Mulheres Negras e pela juventude negra a implementar, de fato, políticas antirracistas e ações afirmativas. Será destacado, neste artigo, o principal protagonista dessa luta que indaga o Estado e, por conseguinte, as suas políticas na construção de um Brasil que tenha a superação do racismo como um dos seus principais objetivos democráticos: o Movimento Negro.

O Movimento Negro brasileiro pode ser considerado um sujeito coletivo e um ator político que, juntamente com outros movimentos sociais operários e populares, surge a partir da década de 70 do século XX, com a forte marca de politização do cotidiano, com formas diferenciadas de expressão e experiências (Gomes, 2017, p. 4755). Um dos ensinamentos desse e dos outros movimentos sociais de caráter identitário que herdamos (mulheres, indígenas, povos do campo, lutas ambientais) é a valorização do cotidiano e da experiência. Eles compreendem que é na luta cotidiana que se trava a resistência.

Como afirma Cardoso (2002, p. 14):

[...] os movimentos populares repudiavam a forma instituída da prática política - vista como manipulação - e privilegiavam as ações diretas para manifestar a sua vontade política.A partir da luta contra as desigualdades sociais e apoiandose na solidariedade entre os oprimidos, os movimentos sociais fizeram da dignidade construída na própria luta o reconhecimento do seu valor e a afirmação da própria identidade: só com a luta se conquista direitos.

O Movimento Negro é composto de várias entidades, de coletivos, grupos e núcleos que dão sentido e significado às lutas antirracistas nacional e internacional. Ele é capaz de reordenar enunciados, articular lutas e desafios. Na sua organização, existem conflitos, contradições, consensos, dissensos, reconhecimento, construção de outros enunciados, ressignificação de palavras e atribuição de novos conceitos e a construção de outra gramática política para falar sobre as relações raciais, o racismo, a diáspora africana, a ancestralidade e a igualdade racial (Gomes, 2017, p. 47-50). Reitera-se neste artigo o que já se disse em outros trabalhos (Gomes, 2017, 2012,2011): o surgimento do Movimento Negro no contexto dos novos movimentos sociais, principalmente os de caráter identitário, trouxe especificidades no contexto das lutas e das reivindicações desencadeadas no Brasil, a partir dos anos 1970. Uma dessas especificidades apontadas por Cardoso (2002) é o olhar e a releitura da História. Segundo o autor: 
Para o Movimento Negro, o cotidiano da população negra é determinado pela estrutura do racismo da sociedade brasileira. Ao emergir na cena nacional a partir da especificidade da luta política contra o racismo que marcou os anos 70, o Movimento Negro teve que buscar na história a chave para compreender a realidade da população negra brasileira. Impelido pela necessidade de negar a história convencional (oficial) e contribuir para a construção de uma nova interpretação da trajetória do povo negro no Brasil é que o Movimento Negro se distinguiu dos demais movimentos sociais e populares. $\mathrm{Na}$ verdade, o Movimento Negro é fruto de uma negatividade histórica" (Cardoso, 2002, p.17).

O Movimento Negro é, portanto, um educador. É ele que fez e faz a tradução intercultural das teorias e das interpretações críticas realizadas sobre a temática racial no campo acadêmico para a população negra e pobre fora da universidade; que articula com intelectuais comprometidos com a superação do racismo encontros, palestras, publicações, minicursos, workshops, projeto de extensão, ciclos de debates, abertos à comunidade; que inspira, produz e ajuda a circular as mais variadas publicações, panfletos, folders, revistas, livros, sites, canais de YouTube, blogs, páginas do Facebook, álbuns, artes, literatura, poesia, abordando a temática racial em sintonia com a diáspora africana. É ele quem pressiona o Estado para adotar políticas de igualdade racial (Gomes, 2017, p.17-18). No seu papel educativo, tal movimento educa e reeduca a sociedade, o Estado e a si mesmo sobre as relações raciais, o racismo e a diáspora africana. E, se é um educador, ele constrói pedagogias. E, se constrói pedagogias, interfere nos processos educativos e nas políticas educacionais. Inspirada pelas reflexões de Arroyo (2003), afirmo que o Movimento Negro brasileiro faz parte do processo de produção da pedagogia dos movimentos sociais. A principal tarefa desse movimento social é a luta contra um fenômeno que o Brasil ainda insiste em dizer que não existe ou, se existe, dá-se de forma mais branda em nosso país do que em outros: o racismo.Se concordamos com o fato de que o Movimento Negro participa e desenvolve processos educativos, identitários, de lutas, transgressões e conflitos, também concordaremos com a afirmação de que ele possui a capacidade de indagar e desafiar as elites do poder, o Estado e suas políticas. E, dentre essas políticas, encontram-se as educacionais.

\section{O MOVIMENTO NEGRO INDAGA AS POLÍTICAS EDUCACIONAIS}

Revista da ABPN • v. 11, Ed. Especial - Caderno Temático: Raça Negra e Educação 30 anos depois: e agora, do que mais precisamos falar? • abril de 2019, p.141-162

DOI 10.31418/2177-2770.2019.v11.c.1.p141-162 
A política educacional pertence ao conjunto das políticas sociais, que se materializam por meio da legislação, das práticas, dos planos e dos projetos educacionais. $^{2}$

Apesar de serem de responsabilidade do Estado, as políticas sociais não se reduzem a ele. São demandadas, discutidas, pleiteadas e acompanhadas pela população, pelos organismos políticos, internacionais, pelos movimentos sociais, pelos sindicatos, pelas associações e por outros coletivos da sociedade.

A política educacional, conquanto parte constitutiva das políticas sociais, envolve interesses e disputas diversos e abarca contradições e tensões. ${ }^{3}$ Ela não se desenvolve sozinha, mas no complexo contexto das relações de poder. Em países muito desiguais como o Brasil, essas políticas trazem em si as tensas relações entre raça, gênero, classe e desigualdade regional. Elas são uma confluência de forças progressistas e conservadoras.Os principais focos de orientação nacionaldas políticas educacionais no Brasilsão a Constituição Federal (CF), a Lei de Diretrizes e Bases da Educação (LDB) e o Plano Nacional de Educação (PNE).Embora a política educacional esteja articulada à aplicação do PNE, destaca-se que, apesar da sua importância, cabe lembrar que o Plano está previsto na CF, e a sua regulamentação é determinada pela LDB. Com duração de dez anos, o PNE deve ser revisto e atualizado.

Segundo a Constituição Federal:

Art. 214. A lei estabelecerá o plano nacional de educação, de duração decenal, com o objetivo de articular o sistema nacional de educação em regime de colaboração e definir diretrizes, objetivos, metas e estratégias de implementação para assegurar a manutenção e desenvolvimento do ensino em seus diversos níveis, etapas e modalidades por meio de ações integradas dos poderes públicos das diferentes esferas federativas que conduzam a I - erradicação do analfabetismo;

\footnotetext{
${ }^{2}$ De acordo com Ferreira e Nogueira (2015, p.105): "Na esfera educacional,várias políticas públicas foram lançadas por todos os setores dogoverno federal para se alcançar os objetivos propostos pela Constituição Federal. A título de exemplo, dentre outras políticas,podem ser citadasas seguintes:a)Fundo de Manutenção e Desenvolvimento do Ensino Fundamental e de Valorização do Magistério(FUNDEF);b) Plano de Desenvolvimento da Escola (PDE); c)Programa de Dinheiro Direto na Escola (PDDE); d) Programa Bolsa Família; e) Programa Nacional de Alimentação Escolar (PNAE); f) Programa Nacional do Livro Didático (PNLD); g) Programa Nacional de Transporte Escolar (PNATE); h) Exame Nacional do Ensino Médio(Enem); i) Sistema de Seleção Unificada(Sisu); j) Programa Universidade para Todos(ProUni); k) Programa Nacional de Reestruturação e Aquisição de Equipamentos para a Rede Escolar Pública de Educação Infantil (Proinfância).OPlanoNacional de Educação é a política públicamais atual e tem como objetivo a melhoria da educação [...]".

${ }^{3}$ Uma observação importante: as políticas educacionais aqui citadas e analisadas correspondem ao período dos governos do Partido dos Trabalhadores (PT), a saber, de 2003 a 2016.
}

Revista da ABPN • v. 11, Ed. Especial - Caderno Temático: Raça Negra e Educação 30 
II - universalização do atendimento escolar;

III - melhoria da qualidade do ensino;

IV - formação para o trabalho;

V - promoção humanística, científica e tecnológica do País;

VI - estabelecimento de meta de aplicação de recursos públicos em educação como proporção do produto interno bruto. (Brasil, 1988, grifos nossos)

De acordo com a LDB:

Art. $9^{\circ}$. A União incumbir-se-á de:

I - elaborar o Plano Nacional de Educação, em colaboração com os Estados, o Distrito Federal e os Municípios;

Art. 10. Os Estados incumbir-se-ão de:

III - elaborar e executar políticas e planos educacionais, em consonância com as diretrizes e planos nacionais de educação, integrando e coordenando as suas ações e as dos seus Municípios;

Art. 11. Os Municípios incumbir-se-ão de:

I - organizar, manter e desenvolver os órgãos e instituições oficiais dos seus sistemas de ensino, integrando-os às políticas e planos educacionais da União e dos Estados (Brasil, 1996, grifos nossos)

Ou seja, a CF e a LDB são os documentos legais que preveem e regulamentam o PNE. Apesar de também sofrerem alterações advindas do Executivo e do Legislativo, impulsionadas pela articulação entre as demandas da sociedade civil organizada e os interesses diversos, ambas apresentam mudanças mais lentas do que o próprio Plano, as quais são acompanhadas de tensões, debates e polêmicas. Quando querem privatizar a educação ou diminuir a ação e a abrangência da educação pública, as forças conservadoras atacam em primeiro lugar a Constituição Federal e propõem mudanças à LDB. Da mesma forma, quando as forças progressistas querem ampliar direitos educacionais e sintonizá-los com a dinâmica das lutas sociais são esses mesmos documentos legais que vão buscar.

É com o olhar na LDB 9.394/06 que pretendo discutir a relação entre o Movimento Negro, as demandas por educação e as políticas educacionais.

No contexto das lutas por direitos e antirracistas, a educação formal sempre foi um foco de atenção e atuação do Movimento Negro brasileiro desde a Abolição da Escravatura. Várias autoras e vários autores já se dedicaram a esse assunto (Gomes, 2011, 2009; Gonçalves, 2011; Lima, 2010; Pereira, 2008; Domingues, 2007; Cruz, 2005; Gonçalves; Silva, 2000, dentre outros). 
Alguns desses autores destacam que as várias iniciativas desenvolvidas pelas entidades negras no século XX inicialmente tinham o caráter de ações mais coletivas, com enfoque nas estratégias de resistência familiares, comunitárias, atreladas a uma visão de integração dos negros e das negras na sociedade de classes. No decorrer dos anos, a ideia de "integração" começa a ser problematizada, e as próprias entidades mudam o seu discurso e a forma de ação política para a denúncia incisiva da presença do racismo na sociedade brasileira. Racismo esse que, na realidade, nunca desejou e admitiu essa tão falada "integração" e interpôs (e ainda interpõe!) uma série de limites a ela. Até mesmo a imigração estrangeira foi implementada como estratégia de Estado no fim do século XIX e início do século XX, na tentativa de embranquecer a nação e tornála "civilizada" aos olhos do mundo, livrando o país da insistente presença das pessoas negras (Gomes, 2017, p.103).

Viver esse processo perverso resultou no amadurecimento político das entidades negras sobre os impactos do racismo ao longo do tempo. Aos poucos, os militantes perceberam que o Estado tinha um papel segregador, racista e excludente, escamoteado pelo discurso de uma igualdade entre as diferentes raças. Essa constatação impôs outra estratégia de luta. O Movimento Negro passa, então, a tensionar ainda mais a relação com o Estado e a sociedade e também cobra desse a responsabilidade pública de combate e de superação do racismo. Exige do Estado a implementação de políticas públicas e, dentre elas, as educacionais, com o foco na garantia do direito de todos e, dentre esses, a população negra. Ou seja, ao universalizar as políticas, o Estado deveria considerar a situação de desigualdade racial e o racismo que incidia sobre as negras e os negros.

Foi a partir dos anos 70 do século XX, na luta contra a ditadura militar e contra o racismo, que o Movimento Negro, na sua organização mais contemporânea, voltou os seus esforços políticos e reivindicatórios de forma mais contundente ao Estado. O combate ao racismo somou-se à luta pela retomada do Estado democrático e de direito. A maior compreensão das imbricações entre raça e classe passou a fazer parte com mais força das reflexões, das denúncias e das demandas desse movimento social. E passou a se incluir também nas negociações e tensões internas entre o Movimento e os demais movimentos populares que, naquela época, ainda não reconheciam a especificidade racial presente na luta contra as desigualdades. 
Com o processo de queda da ditadura militar, da reabertura política no Brasil nos anos 80 do século XX, da realização da Assembleia Nacional Constituinte (ANC) e da promulgação da Constituição Federal, em 1988 (CF), as entidades do Movimento Negro compreenderam melhor os desafios presentes na relação entre a luta antirracista, a democracia e as políticas públicas. $\mathrm{O}$ acúmulo das ações e iniciativas negras em relação à educação é redimensionado pelo Movimento Negro como demandas específicas e políticas ao Estado brasileiro e suas instituições. A questão racial, o combate ao racismo na sociedade e na escola, antes pautas específicas do Movimento Negro, começam a emergir na cena pública e política nacional como parte da demanda por um Brasil e uma escola democráticos.

Dessa forma, a Frente Negra Brasileira, o Teatro Experimental do Negro, os Congressos Afro-Brasileiros, as experiências de escolas construídas em terreiros de candomblé, as intervenções nos currículos escolares, a formação pedagógica para docentes junto com entes federados, os projetos pedagógicos desenvolvidos por blocos afros e escolas de sambas, a introdução do estudo da História da África e das Culturas Afro-Brasileiras nos currículos, a releitura crítica dos manuais didáticos denunciando os estereótipos raciais, dentre outras, foram algumas iniciativas educacionais desenvolvidas pelo Movimento Negro ao longo do século XX como forma de combater o racismo e de implicar o poder público nessa luta.

\section{O ESTADO BRASILEIRO E SUA RESPONSABILIDADE NA LUTA ANTIRRACISTA}

Na década de 1980, no período de término da ditadura militar e início da redemocratização do país, o Movimento Negro participou de um intenso processo de mobilização, pressionando para que o Estado brasileiro assumisse publicamente que o racismo é crime epara que todas as instituições do Estado democrático que se reconstituía se comprometessem com a sua superação.

Na convivência com os demais movimentos sociais, com o novo sindicalismo e diante da emergência de partidos progressistas, após a ditadura militar, o Movimento Negro compreendeu que era necessário garantir que a nova Constituição Federal, a ser construída por meio de um esforço nacional, considerasse a prática do racismo como um crime, além de incluir na Carta Magna uma série de direitos para a população negra

Revista da ABPN • v. 11, Ed. Especial - Caderno Temático: Raça Negra e Educação 30 
como forma de construir um país realmente democrático.Nesse processo, a decisão de que a questão racial teria de ser abordada durante a Assembleia Nacional Constituinte (ANC) foi uma reivindicação do Movimento Negro, que passou a organizar eventos preparatórios de participação na Constituinte.

Segundo Rodrigues (2005, p. 49):

O movimento negro, a partir de 1985, organizou encontros municipais e estaduais com o objetivo de refletir a participação do negro no processo constituinte. Entre esses, destaca-se o Primeiro Encontro Estadual 'O negro e a constituinte', realizado em julho de 1985 na Assembleia Legislativa de Minas Gerais. Essas reflexões prolongaram-se por todo o ano de 1986, culminando com a realização, em Brasília, da Convenção Nacional 'O Negro e a Constituinte', da qual se originou um documento sintetizando os Encontros Regionais ocorridos em várias unidades da Federação.

Ainda de acordo com a autora:

A articulação do Movimento Negro que deu origem à determinação pelo Regimento Interno da Constituinte de que a temática racial seria abordada agradou às organizações do movimento negro, que acompanhavam esse processo com expectativa, mesmo com a percepção de que o espaço destinado a essa discussão de início mostrava-se bastante limitado e da errônea abordagem da temática como minoria, como uma questão de menor importância.

A discussão seria feita na 'Subcomissão dos Negros, Populações Indígenas, Pessoas Deficientes e Minorias', que integrava a Comissão Temática "Da Ordem Social" (Rodrigues, 2005, p.51).

A autora destaca, com justiça, a importância do papel desempenhado por alguns interlocutores do Movimento Negro,que, durante o debate e a articulação políticos, estavam mais próximos e atuavam, de alguma forma, representando os interesses da comunidade negra, como a senadora Benedita da Silva e os deputados federais Luiz Alberto Caó, Edmilson Valentim e Paulo Paim (Rodrigues,2005, p.52).

Ao final de um longo processo, lamentavelmente o documento final da $\mathrm{CF}$ acabou por reduzir as pautas da questão racial levadas pelo Movimento Negro e pelos aliados da luta antirracista. Para Rodrigues (2005, p. 55-56), o texto constitucional:

[...] apenas sinalizou a necessidade de que o currículo escolar refletisse a pluralidade racial brasileira, mas retirou as propostas de obrigatoriedade do estudo da Cultura e História da África dos currículos nos três níveis de ensino e a proposta de reformulação dos currículos de História do Brasil.

Revista da ABPN • v. 11, Ed. Especial - Caderno Temático: Raça Negra e Educação 30 
As reivindicações do movimento negro para a educação de alteração curricular foram consideradas muito específicas devendo ser tratadas em leis ordinárias, restando a recomendação de que o currículo escolar refletisse a pluralidade racial brasileira, como sugeriu a emendaapresentada pelo constituinte Geraldo Campos (PMDB), que caracterizou a ênfase do ensino de história das populações negrascomo discriminatória.

De forma integral, na $\mathrm{CF} / 1988$, permaneceram no texto as propostas sobre quilombos e a criminalização do racismo,mesmo assim, a última só foi aprovada devido à mobilização do movimento negro em torno da questão e pelas intensas articulações políticas realizadasprincipalmente por Carlos Alberto Caó na Comissão de Sistematização, onde inicialmente a proposta foi rejeitada por ser considerada uma ameaça à liberdade de expressão.

Embora todas as articulações e tentativas do Movimento Negro por uma pauta emancipatória da questão racial na Constituição de 1988 tenham sido empreendidas, o resultado não foi o que se esperava. A tensão entre o universal e o particular, a raça e a classe novamente venceu e está expressa na lei até hoje.As lutas históricas do Movimento Negro apontadas por Rodrigues (2005) e debatidas desde a ANC pelo Movimento Negro e seus aliados, tais como o reconhecimento, por parte do Estado, das comunidades negras remanescentes de quilombos e o título de propriedade definitiva de suas terras, a criminalização da prática do racismo, do preconceito racial e de qualquer discriminação atentatória aos direitos humanos e uma educação comprometida com o combate ao racismo e a todas as formas de discriminação, que valorizasse e respeitasse a diversidade, assegurando a obrigatoriedade do ensino da história das populações negras do Brasil, foram parcialmente contempladas. Ao final, ficaram restritas aos art. $5^{\circ}$, inciso XLII, 215, 216 e 242, bem como ao art. 68 das Disposições Constitucionais Transitórias (p.52, 53).

Segundo o art. $5^{\circ}$, inciso XLII:

Art. $5^{\circ}$ Todos são iguais perante a lei, sem distinção de qualquer natureza, garantindo-se aos brasileiros e aos estrangeiros residentes no País a inviolabilidade do direito à vida, à liberdade, à igualdade, à segurança e à propriedade, nos termos seguintes:

XLII -a prática do racismo constitui crime inafiançável e imprescritível, sujeito à pena de reclusão, nos termos da lei; (Brasil, 1988)

Sem dúvida, tornar a prática do racismo um crime fez avançar a luta antirracista. Foi uma conquista que ultrapassou o que estava previsto na Lei n.1.390, Lei Afonso Arinos, criada em 1951, e que proibia a discriminação racial no país. Apesar do mérito 
da sua existência, é consenso entre os juristas e os advogados de que esta lei não era suficiente, uma vez que não era rigorosa com as punições. Casos explícitos de impedimento dos direitos das pessoas negras a adquirir um emprego, a transitar e a entrar em locais públicos e privados, escolas, a ter acesso a serviços públicos não eram cobertos pela Lei Afonso Arinos.

Tornar o racismo como crime inafiançável também vai além da Lei n.7.716/89, mais conhecida como "Lei Caó", criada em 1989, segundo a qual seriam punidos os crimes resultantes de discriminação ou preconceito de raça, cor, etnia, religião ou procedência nacional.

Retomar as leis que antecederam o inciso XLII do art. $5^{\circ}$ da Lei Caó é reconhecer que a sua existência, hoje, mesmo com os limites que possui, é resultado da atuação do Movimento Negro, de parlamentares e dos demais partícipes da luta antirracista durante o processo da Assembleia Nacional Constituinte (ANC).

No país no qual o mito da democracia racial age na estrutura e no imaginário social conseguir que o Estado reconhecesse a existência do racismo como um grave impedimento do exercício de direitos dos cidadãos e cidadãs brasileiros é um passo significativo, que deu origem a uma série de demandas, jurisprudência e empenho pelo aprimoramento da lei.

Apesar desse importante passo, avançamos pouco na efetivação de um texto constitucional emancipatório no que se refere à questão racial, de modo geral, e à educação, em específico. A histórica demanda do Movimento Negro para que o currículo das escolas reconhecesse a importância do estudo da história da África e das questões afro-brasileiras como uma das formas de superação do racismo não foi contemplada pela CF.

Como resultado, o texto constitucional aprovado contemplou o tema da maneira mais genérica e universal possível: "Art. $242-\S 1^{\circ} \mathrm{O}$ ensino da História do Brasil levará em conta as contribuições das diferentes culturas e etnias para a formação do povo brasileiro" (Brasil, 1988).

A questão racial também não foi contemplada no texto específico da Seção I, Da Educação. Ela só aparece na Seção II desse capítulo, quando esse se refereà Cultura. Vejamos:

Revista da ABPN • v. 11, Ed. Especial - Caderno Temático: Raça Negra e Educação 30 
Art. 215. O Estado garantirá a todos o pleno exercício dos direitos culturais e acesso às fontes da cultura nacional, e apoiará e incentivará a valorização e a difusão das manifestações culturais.

$\S 1^{\circ} \mathrm{O}$ Estado protegerá as manifestações das culturas populares, indígenas e afro-brasileiras, e das de outros grupos participantes do processo civilizatório nacional.

$\S 2^{\circ}$ A lei disporá sobre a fixação de datas comemorativas de alta significação para os diferentes segmentos étnicos nacionais.

$\S 3^{\circ}$ A lei estabelecerá o Plano Nacional de Cultura, de duração plurianual, visando ao desenvolvimento cultural do País e à integração das ações do poder público que conduzem à:

Inciso V: valorização da diversidade étnica e regional; (BRASIL, 1988).

Art. 216. Constituem patrimônio cultural brasileiro os bens de natureza material e imaterial, tomados individualmente ou em conjunto, portadores de referência à identidade, à ação, à memória dos diferentes grupos formadores da sociedade brasileira, nos quais se incluem:

$\S 5^{\circ}$ Ficam tombados todos os documentos e os sítios detentores de reminiscências históricas dos antigos quilombos. (Brasil, 1988, grifos nossos)

Embora não seja uma referência específica à educação, o art. 68, do Ato das Disposições Constituições Transitórias, também foi fruto de demandas e articulações do Movimento Negro. Ele deu força à aprovação do Decreto n.4.887/03 (regularização dos territórios quilombolas) e, posteriormente, à demanda de construção das Diretrizes Curriculares Nacionais para a Educação Escolar Quilombola (Parecer CNE/CEB 16/2012 e Resolução CNE/CP 08/2012): “Art. 68. Aos remanescentes das comunidades dos quilombos que estejam ocupando suas terras é reconhecida a propriedade definitiva, devendo o Estado emitir-lhes os títulos respectivos" (Brasil, 1988).

O que a princípio pode parecer uma perda, ou seja, a questão racial somente ser contemplada em lugares específicos e pouco expressivos no texto final da Constituição Federal, tem também a possibilidade de ser entendido como a estratégia possível do Movimento Negro no contexto das disputas travadas durante o processo da Assembleia Nacional Constituinte e de aprovação da CF.

Ao perceber que o campo de forças não estava totalmente do lado da luta contra o racismo, foi necessário aos militantes do Movimento Negro negociar para que a questão racial não fosse totalmente invisibilizada na lei. Algo teria de ser garantido para que fosse viável continuar a luta mais à frente, com outros contornos e demandas pelo seu aprimoramento.

Essa estratégia produziu resultados. Após a promulgação da $\mathrm{CF}$, os setores políticos e sociais se organizaram em torno das Leis Ordinárias, a fim de aprimorar o

Revista da ABPN • v. 11, Ed. Especial - Caderno Temático: Raça Negra e Educação 30 anos depois: e agora, do que mais precisamos falar? • abril de 2019, p.141-162

DOI 10.31418/2177-2770.2019.v11.c.1.p141-162 
que havia sido institucionalizado na Carta Magna. Os Estados, os Municípios e o Distrito Federal se organizaram na construção das Constituições Estaduais e Leis Orgânicas, as quais deveriam seguir as orientações da Constituição Federal, tendo liberdade de proposições regionais e locais.

Sendo assim, ter o racismo como crime inafiançável, garantir um lugar da questão racial como parte do patrimônio cultural brasileiro e garantir a propriedade definitiva aos remanescentes de comunidades quilombolas que estivessem ocupando suas terras como dever do Estado brasileiro foram conquistas estratégicas e possíveis do Movimento Negro, à época, e que não devem ser desprezadas.

\section{A QUESTÃO RACIAL E A LDB}

Contudo, isso não significou acomodação. Logo após a sanção do novo texto constitucional, desencadeou-se o processo de elaboração das Leis Complementares e Ordinárias. Iniciou-se, portanto, o processo de discussão de uma importante Lei Ordinária: a nova Lei de Diretrizes de Bases da Educação. As negras e os negros organizados no Movimento Negro, nos sindicatos e nos partidos políticos voltaram os seus esforços para a inserção do estudo da História e Cultura Africana e Afro-Brasileira na LDB como eixos da educação nacional e forma de combate ao racismo. A atuação se deu, a partir de então, no Fórum Nacional em Defesa da Escola Pública na LDB. Assim como no processo da Assembleia Nacional Constituinte, o embate político centrava-se entre o Fórum, formado por 26 entidades (científicas, sindicais e estudantis, de especialistas de educação, de secretários estaduais de educação e de dirigentes municipais de educação), e as entidades que representam o ensino privado, a Confederação Nacional dos Estabelecimentos de Ensino (Confenen), do lado do grupo empresarial, e do lado do grupo confessional, a Associação de Educação Católica (AEC), congregando escolas e professores dos ensinos fundamental e médio, e a Associação Brasileira de Escolas Superiores Católicas (ABESC), congregando educadores e escolas superiores católicas (Oliveira, 1997).

É ainda Rodrigues (2005, p. 67-69) que analisa como ocorreu a disputa política pela inserção da questão racial na Lei n.9.394/96. Ela foi marcada pela não aprovação pelas entidades formadoras do Fórum da participação do Movimento Negro e de outros movimentos sociais. Somente as organizações "clássicas" continuaram presentes, o que

Revista da ABPN • v. 11, Ed. Especial - Caderno Temático: Raça Negra e Educação 30 
significou uma redução do espírito democrático de um fórum com os objetivos para os quais ele foi organizado. Segundo a autora, durante as discussões e as negociações, houve semelhança entre o resultado da análise de conteúdo do projeto de lei da LDB do Senado, no que diz respeito à abordagem da questão racial, e a proposta consolidada na Câmara dos Deputados. O diferencial se estabeleceu na segunda fase de elaboração da lei. Houve a participação da senadora Benedita da Silva, representando o Movimento Negro, na apresentação e na defesa de propostas de reformulação do ensino de História do Brasil e da obrigatoriedade em todos os níveis educacionais da "História das Populações Negras do Brasil”. Contudo, ambas as proposições foram negadas com a justificativa de que haveria uma base nacional comum para a educação, o que tornaria desnecessária a existência de garantia de um espaço exclusivo para a temática racial (RODRIGUES, 2005, p.69). ${ }^{4}$

A conclusão da autora supracitada é de que a negação dos efeitos perversos do racismo na sociedade, somada à concepção unicultural do Brasil, defendida pelo último relator da LDB, Darcy Ribeiro, não só reafirmou o mito da democracia racial no texto da lei, como também negou o compromisso do Estado brasileiro com a correção de desigualdades raciais históricas e violentas (Rodrigues, 2005, p.68-69).Rodrigues (2005, p.70) ainda nos alerta para as ambiguidades do racismo brasileiro. Ela analisa que o parecer negativo às propostas defendidas pela senadora Benedita da Silva foi apresentado concomitantemente à realização da Marcha Zumbi dos Palmares em Brasília, no ano de 1995, em que foram denunciados o racismo, o eurocentrismo, a cultura eurocêntrica e homogeneizadora do Brasil e as formas como afetam e se fazem presentes na educação brasileira. Ou seja, a demanda por uma educação antirracista e pelo ensino de história da África e das populações negras no Brasil, que fazia parte das reivindicações do coletivo de entidades negras durante a Marcha Zumbi dos Palmares, ocorreu no mesmo momento em que o tema era debatido e recebido com resistência no contexto das discussões da nova LDB. Fico a imaginar a sensação de frustração e raiva dos militantes negros quando o texto da LDB foi finalizado e aprovado, em 1996, com a

\footnotetext{
${ }^{4}$ Guardadas as devidas proporções, algo semelhante acontece atualmente nas discussões sobre a Base Nacional Comum Curricular estabelecidas pelo Ministério da Educação (MEC) (após o golpe parlamentar de 2016), o Conselho Nacional de Educação e as entidades organizadas da sociedade civil. O discurso universalista novamente se sobrepõe em detrimento do trato específico e afirmativo do cumprimento da LDB alterada pela Lei n.10.639/03, com a introdução da história e da cultura afro-brasileira e africana nos currículos.
} 
diluição das principais pautas pelas quais tanto lutaram. E como deve ter sido difícil admitir que o discurso de que a especificidade da questão racial na educação seria contemplada pela Lei Ordinária, dito durante o processo da Assembleia Nacional Constituinte por vários parlamentares, não passou de uma estratégia para desviar a atenção ao tema e diminuir a pressão. Na realidade, houve total descompromisso dos políticos e da política.

\section{RESISTÊNCIA E LUTA... SEMPRE!}

Essa situação da educação se repetiu com outros temas nacionais nos quais o Movimento Negro atuou na busca de legislações que garantissem direitos dos negros no trabalho, na saúde, na política de moradia. A ideia de que a questão racial estaria contemplada nas políticas universais e, principalmente, no combate às desigualdades sociais se tornou o mote da esquerda e da direita após a promulgação da Constituição de 1988. Lamentavelmente, nisso as duas alas concordaram, e alguns grupos continuam concordando até hoje, em pleno século XXI e após o golpe parlamentar de 2016.Esse processo resultou em uma inflexão do Movimento Negro nas suas estratégias de luta. Não mais a defesa da ideia deinserção dos negros na sociedade de classes e tampoucoa aposta de que a questão racial e o combate ao racismo seriam contemplados se estivessem inseridos nas políticas públicas universais.

O Movimento Negro reformulou a sua narrativa e suas reivindicações e passoua requerer políticas específicas de combate ao racismo na educação, na saúde, no mercado de trabalho, dentre outros. O contato com as organizações negras norte-americanas e o conhecimento das políticas de ações afirmativas nos EUA e em outros países trouxeram novos aprendizados para esse movimento social no fim dos anos 1990. O acirramento do neoliberalismo e do capitalismo impôs o aumento da pobreza, do desemprego e da fome de forma contundente na vida das pessoas negras, o que exigiu forte atuação das entidades negras no Brasil e no mundo. Essa recebeu apoio internacional, protagonizado pela ONU, a qual passa a cobrar e a fazer pressão sobre os Estados-membros por um posicionamento público quanto ao combate ao racismo e a toda forma de discriminação. Tudo isso contribuiu para uma mudança de rumo e para tornar a ação do Movimento Negro mais incisiva. A realização da Marcha Zumbi dos Palmares, em 1995, deixou ensinamentos importantes para a nova articulação política desse movimento. Além

Revista da ABPN • v. 11, Ed. Especial - Caderno Temático: Raça Negra e Educação 30 anos depois: e agora, do que mais precisamos falar? • abril de 2019, p.141-162

DOI 10.31418/2177-2770.2019.v11.c.1.p141-162 
disso, os anos que sucederam 1995 foram marcados por mudanças nacionais importantes, culminando, em 2002, com a vitória do Partido dos Trabalhadores (PT) e a ascensão da esquerda pela primeira vez ao Executivo federal. Em 2001, o Brasil se fez representar na Conferência de Durban, na África do Sul, e pela primeira vez os dados de raça/cor foram desagregados pelos pesquisadores do Ipeae tornados públicos. Uma profunda desigualdade racial foi revelada em todas as áreas e setores abordados pela investigação. Não havia como negar o racismo e a desigualdade racial, já que os dados oficiais confirmavam a denúncia histórica do Movimento Negro (Henriques, 2001).Foram esses dados que a diplomacia brasileira levou para Durban, seguida por militantes do Movimento Negro e outros movimentos sociais. Tais dados, já discutidos previamente pela militância nas conferências preparatórias pré-Durban, foram um importante instrumento político de negociação do Movimento Negro com as forças de esquerda que almejavam ganhar as eleições presidenciais.

Foi nesse processo de articulação de forças que o então candidato, Luiz Inácio Lula da Silva, saiu vitorioso das eleições presidenciais. Em continuidade às pressões, o Movimento Negro lutou para que, no conjunto dos ministérios e das políticas de Estado do primeiro governo de esquerda do Brasil, contemplasse a questão racial e o combate ao racismo em lugar de destaque. E é assim que se configura a alteração da Lei n.9.394/96 (LDB) pela Lei n.10.639/03 (obrigatoriedade do ensino de História da África e das Culturas Afro-Brasileiras) nas escolas públicas e privadas dos ensinos fundamental e médio. A lei foi sancionada, em 2003, junto com a criação da Secretaria de Políticas de Promoção da Igualdade Racial (Seppir). Mesmo assim, esta última só foi criada na segunda rodada de ministérios apresentados pelo então presidente, sob nova pressão do Movimento Negro. Em 2004, assistimos à criação da Secretaria de Educação Continuada, Alfabetização e Diversidade (Secad) no Ministério da Educação (MEC), a qual mais tarde passou a incorporar as questões da inclusão e se tornou Secadi.

Fruto das reivindicações de vários movimentos sociais pelo reconhecimento das suas questões nos programas e políticas educacionais, a Secadi foi a secretaria do MEC responsável pela implementação de uma série de ações voltadas não somente à alfabetização de jovens e adultos, mas também à educação dos povos do campo, negros, indígenas, quilombolas e de temas como meio ambiente, sexualidades, educação integral. Uma série de editais, programas, projetos e pesquisas promovidos pelo MEC 
ou impulsionados por esse ministério foi desenvolvida a partir de então. E a Secadi viveu no interior do MEC todas as tensões, disputas e luta por reconhecimento pelas quais os sujeitos que essa representava viviam na sociedade e no campo educacional.

A alteração da LDB pela Lei n. 10.639/03 é, portanto, de uma importância simbólica e política que extrapola os próprios artigos nela explicitados. ${ }^{5}$ Ela representa o fechamento de um ciclo de lutas antirracistas do Movimento Negro na educação e marca o início de outro, voltado para a implementação dessas políticas, de maneira oficial, no campo da educação básica e superior. A sua regulamentação pela Resolução CNE/CP n. 01/2004 e pelo Parecer CNE/CP n. 03/2004, sob a relatoria da professora Petronilha Beatriz Gonçalves e Silva (UFSCar), quando esta ocupou uma cadeira na Câmara de Educação Superior do Conselho Nacional de Educação (CNE), indicada pelo Movimento Negro, coroou uma longa trajetória desse movimento social e dos demais parceiros da luta antirracista pela inclusão, pelo direito e pela legitimidade da questão racial nas políticas educacionais.

Embora reconheça que a radicalidade dessa alteração da LDB e todo o histórico de lutas, esforços e articulações que ela congrega ainda não estão contemplados com a radicalidade necessária na educação brasileira, não há como deixar de reconhecer os avanços advindos após a sanção da lei e a aprovação do parecer e da resolução do CNE que a regulamentaram. Assistimos a mudanças nas práticas pedagógicas, na produção de material didático qualificado e na literatura infanto-juvenil voltada às pessoas negras, com personagens e situações vividas por elas, iniciativas de formação continuada de professores da educação básica, tais como cursos de especialização, aperfeiçoamento, extensão, atualização, desenvolvimento de pesquisas, editais do MEC para o fortalecimento dos Núcleos de Estudos Afro-Brasileiros nas universidades, incremento da realização de pesquisas, encontros e seminários sobre a temática, introdução de disciplinas na educação básica e superior com ênfase nas questões africanas e afrobrasileiras, maior reconhecimento da desigualdade racial na sociedade e na educação, visibilidade aos professores negros como sujeitos de conhecimento, dentre outros.A alteração da LDB pela Lei n.10.639/03 causou inflexão quer na discussão quer na

\footnotetext{
${ }^{5}$ Em 2008, foi sancionada a Lei n.11.645/08, que incluiu também as populações indígenas no art. 26 A, da Lei de Diretrizes e Bases da Educação.
}

Revista da ABPN • v. 11, Ed. Especial - Caderno Temático: Raça Negra e Educação 30 anos depois: e agora, do que mais precisamos falar? • abril de 2019, p.141-162 DOI 10.31418/2177-2770.2019.v11.c.1.p141-162 
relação entre políticas educacionais, desigualdade racial, reconhecimento e superação do racismo.

\section{UM NOVO CICLO DO MOVIMENTO NEGRO}

É possível dizer que a trajetória histórica do Movimento Negro em prol da educaçãofechou um ciclo com a aprovação da alteração da LDB pela Lei n.10.639/03. Depois disso, de 2003 a 2016, abriu-se e fechou-se outro. A partir de 2003, vivemos o contexto de implementação dessa legislação (ainda que de maneira irregular) e de uma série de ações, programas e políticas de igualdade racial, coordenadas pelo governo federal e sob a responsabilidade da Seppir e da Secadi (Carreira, 2017).Nesse novo ciclo das políticas, também se configura outro perfil do Movimento Negro, e suas ações se tornam mais focadas. Trata-se de um Movimento Negro mais jovem, com maior presença no campo educacional como docente e discente da educação básica e do ensino superior. Um movimento no qual os seus integrantes pertencem a novos coletivos, e não somente às entidades políticas históricas. Um Movimento Negro mais fluido, com uma inserção cultural na periferia, com fortes vínculos com o universo da cultura, das artes, das tecnologias e das redes sociais.

Nesse processo, a ampliação do conceito de Movimento Negro se faz necessária se a ele queremos incluir, além das entidades tradicionais ligadas ao mundo da política, da defesa dos povos quilombolas, de matriz africana e grupos do Movimento Hip-Hop, a juventude negra e periférica, as jovens militantes negras, inseridas nas redes sociais, com domínio e presença nas mídias alternativas e os universitários negros cotistas ou não. Se a nossa concepção de Movimento Negro se alargar em sintonia com os movimentos sociais e as ações coletivas do nosso tempo e do nosso século, entenderemos que o fato de serem homens e mulheres negros, que se posicionam publicamente na luta antirracista com uma postura de denúncia, reivindicação e propostas de superação do racismo, nos coloca diante do Movimento Negro do século XXI.

Movimento esse que incorpora diferentes gerações, identidades negras, formas de ação, mas que mantém consenso sobre o reconhecimento da nossa ancestralidade africana, a perversidade estrutural do racismo e sua repercussão violenta na vida das pessoas negras. Também tem concordância em relação à responsabilidade do Estado de 
continuar implementando políticas de igualdade racial e de ações afirmativas como uma das formas de correção de desigualdades históricas. É ainda consenso a urgente superação do genocídio da juventude negra e da violência contra a mulher negra.

Esse Movimento Negro do século XXI luta contra o racismo, o patriarcado, o machismo, a LGBTfobia e o epistemicídio. Ele é muito marcado pela luta das mulheres negras, principalmente as jovens, na construção da pauta de luta do feminismo negro, o qual foi amplamente visibilizado, em 2015, com a realização da Marcha das Mulheres Negras, no mês de novembro, em Brasília, os eventos de empoderamento crespo nas diferentes cidades do país, as marchas de orgulho crespo, as várias performances afros que envolvem a articulação entre gênero, raça e sexualidades.

Tal Movimento Negro do século XXI impacta, indaga e desafia as políticas públicas brasileiras, em especial, as educacionais. Ele cobra dos governos e do Estado o cumprimento dos acordos internacionais voltados para a superação do racismo, a garantia dos direitos humanos e das mulheres, enfatizando o recorte racial de todas essas pautas.

\section{CONCLUINDO}

Por isso, após 30 anos da publicação de Caderno de Pesquisa n. 63, pela Fundação Carlos Chagas, ao nos perguntarmos sobre o que mais poderemos fazer nessa caminhada de luta pela educação antirracista, o nosso olhar se volta para a trajetória dinâmica e corajosa do Movimento Negro, entendida como parte da resistência democrática. Mas o que vem a ser a resistência democrática? Para o povo negro, é aquela que combina a força da herança ancestral africana e afro-brasileira, a luta histórica do Movimento Negro e dos negros em movimento, os conhecimentos produzidos e sistematizados pelo Movimento Negro, as novas formas de lutas negras do século XXI, o acúmulo teórico-acadêmico dos negros e das negras intelectuais, a energia e a criatividade da juventude negra, a garra das mulheres negras do passado e do presente.Elase alicerça em alguns princípios e se configura em algumas ações, a saber:

- reconhecer a sabedoria e as lutas ancestrais;

- reconhecer as novas formas de organização negra e suas pautas de luta;

- superar a visão de que temos hierarquias entre desigualdades e opressões nas lutas emancipatórias, compreendendo como a questão da diversidade e das diferenças tem 
sido manipulada no contexto das relações de poder a ponto de levar os próprios coletivos progressistas a disputar entre si direitos e emancipação;

- compreender que capitalismo, racismo, patriarcado e pobreza possuem o mesmo passado colonial, mas operam de forma e intensidades diferenciadas. Por isso, a sua superação tem de ter como ponto comum a emancipação social, considerando como cada coletivo sofre e vive as opressões e as desigualdades específicas, reconhecendo sua trajetória de lutas, incorporando suas reivindicações específicas;

- continuar lutando pelo enraizamento das políticas de ações afirmativas voltadas para a população negra, pressionando o Estado brasileiro para que ele invista recursos públicos, de fato, para a sua efetividade;

- lutar contra o racismo religioso, o recrudescimento das formas de racismo on-line e off-line, o genocídio da juventude negra, a violência contra a mulher negra e a população afro-LGBT;

- construir outras alianças com movimentos sociais, ações coletivas, partidos de esquerda e forças emancipatórias na luta contra o racismo, a pobreza, o machismo, o ataque aos quilombolas, aos indígenas e aos povos do campo que lutam historicamente pelo seu direito à terra;

- lutar a fim de que o Estado reconheça que, para a superação do racismo, não basta apenas buscar a igualdade social. Elatem de estar articulada com a equidade, a igualdade racial, a justiça social e cognitiva.

Estamos em tempos de reedição do racismo no mundo, que acompanha o desenvolvimento da sociedade atual, a globalização capitalista, o avanço da lógica de mercado, a quebra das fronteiras possibilitada pelo universo web, pelas redes sociais, pelas novas tecnologias. Reedição da aversão às diferenças, ao povo, aos pobres, aos negros, aos movimentos LGBT, aos deficientes, às mulheres, aos indígenas, aos quilombolas, aos povos do campo e das florestas. Aversão à democracia.

Nesse contexto, muitas pessoas se mostram desanimadas, desiludidas e sem esperança. Momentos de abatimento também incidem, por vezes, sobre mim. O contexto de retrocessos é especialmente duro para quem vive na pele (literalmente!) o saber-se negra. Mas, para aquelas e aqueles que, além de saberem-se negros, saboreiam o fato de sermos frutos de uma história ancestral de resistência, herdeiros de povos que foram obrigados, à força, a deixar a sua terra e atravessar o oceano Atlântico no porão 
escuro e insalubre de um navio negreiro, não há espaço para a desistência. Temos de reinventar o presente e continuar a resistir. Uma das formas de resistir é investir no momento presente e compreender que somos chamados a agir nele. Rememorar a nossa ancestralidade africana não pode nos imobilizar no saudosismo. E projetar um futuro melhor significa ter os pés firmes no presente, a fim de construir um porvir mais digno. Conhecer e compreender a trajetória do Movimento Negro na sociedade, principalmente as formas como ele tem indagado e reconfigurado as políticas educacionais - em meio a tantos limites e desafios -, é um convite à reflexão sobre as interconexões possíveis entre passado, presente e futuro, com o olhar sempre voltado para a emancipação social.

\section{REFERÊNCIAS}

ARROYO, Miguel G. Pedagogias em movimento- o que temos a aprender dos movimentos sociais? Currículo sem Fronteiras, v.3, n.1, p.28-49, jan./jun. 2003.

BRASIL. Constituição da República Federativa do Brasil, promulgada em 5 de outubro de 1988. Diário Oficial da União, Poder Executivo, Brasília, DF, 5 out. 1988.Disponível em: <http://www.planalto.gov.br>. Acesso em: 3 nov. 2017.

BRASIL. Lei de Diretrizes e Bases da Educação, Lei $n$ 9.394/96. Disponível em: <http://www.planalto.org.br>.Acesso em: 3 nov. 2017.

CARDOSO, Marcos. O movimento negro. Belo Horizonte, Mazza Edições,2002.

CARREIRA, Denise. Igualdades e diferenças nas políticas educacionais: a agenda das diversidades nos governos Lula e Dilma. São Paulo: Ação Educativa, 2017.

CRUZ, Mariléia dos Santos. Uma abordagem sobre a história da educação dos negros. In: ROMÃO, Jeruse (Org.). História da educação dos negros e outras histórias. Brasília, DF: MEC; Secad, 2005. p. 21-33.

DOMINGUES, Petrônio. Movimento negro brasileiro: alguns apontamentos históricos.Tempo, Niterói, v. 12, n. 23, p. 100-122, 2007.

FERREIRA, Luiz Antonio Miguel; NOGUEIRA, Flávia Maria de Barros. Impactos das políticas educacionais no cotidiano das escolas públicas. Arquivo Brasileiro de Educação. Belo Horizonte: Programa de Pós-Graduação da PUC-Minas, v. 3, n.5, p.102-129, jan,/jul. 2015.

GOMES, Nilma Lino. O movimento negro educador: saberes construídos nas lutas por emancipação. Petrópolis:Vozes, 2017.

GOMES, Nilma Lino. Movimento negro e educação: ressignificando e politizando a raça.Educação e Sociedade, Campinas, v. 33, n. 120,p. 727-744, 2012.

GOMES, Nilma Lino. O movimento negro no Brasil: ausências, emergências e a produção dos saberes. Política \& Sociedade, Florianópolis, v. 10, n. 18, p. 133-154, abr. 2011.

Revista da ABPN • v. 11, Ed. Especial - Caderno Temático: Raça Negra e Educação 30 
GOMES, Nilma Lino. Limites e possibilidades da implementação da Lei 10.639/03 no contexto das políticas públicas em educação. In: PAULA, M.; HERINGER, R. (Org.). Caminhos convergentes: Estado e sociedade na superação das desigualdades raciais no Brasil. Rio de Janeiro: Heinrich BöllStiftung; ActionAid, 2009. p. 39-74.

GONÇALVES, Luiz Alberto Oliveira. Pensar a educação, pensar o racismo no Brasil. In: FONSECA, M.V.; SILVA, C.M.N.; FERNANDES, A.B. (Org.). Relações étnico-raciais e educação no Brasil. Belo Horizonte: Mazza Edições, 2011. p. 93-144.

GONÇALVES, Luiz Alberto Oliveira.; SILVA, Petronilha Beatriz Gonçalves e. Movimento negro e educação. Revista Brasileira de Educação, São Paulo, n. 15, p. 134-158, set./dez. 2000. HENRIQUES, Ricardo. Desigualdade racial no Brasil: evolução das condições de vida na década de 1990. Rio de Janeiro: Ipea, 2001.

LIMA, Ivan C. Trajetos históricos das pedagogias promovidas pelo movimento negro no Brasil. In: NOGUEIRA, João Carlos; PASSOS, Joana.; SILVA, V.B.M. Negros no Brasil: política, cultura e pedagogias. Florianópolis: Atilènde, 2010. p. 3-63.

OLIVEIRA, R.T.C. A LDB e o contexto nacional: o papel dos partidos políticos na elaboração dos projetos - 1988 a 1996. 370 f. Tese (Doutorado em Educação) -Faculdade de Educação, Universidade Estadual de Campinas, Campinas, 1997.

PEREIRA, Amauri Mendes. Trajetórias e perspectivas do movimento negro brasileiro. Belo Horizonte: Nandyala, 2008.

RODRIGUES, Tatiane Consentino. Movimento negro no cenário brasileiro: embates e contribuições à política educacional nas décadas de 1980 e 1990. Dissertação (Mestrado em Sociologia) -Instituto de Ciências da Educação e Ciências Humanas, Universidade Federal de São Carlos, São Carlos, 2005. 